\title{
HUBUNGAN ANTARA IKLIM ORGANISASI DAN ETOS KERJA DENGAN KINERJA DOSEN AKADEMI KEPERAWATAN DI JAKARTA PUSAT
}

\author{
Roosmyaty Patras*
}

\begin{abstract}
The objective of this research is to study the relationship between organizational climate and work ethic with the lecture job performance. The study was conducted at Nursing Academy at Center Jakarta. This research using quantitative approach with survey method. Total samples using in this research 54 lectures that selected through simple random sampling. Data collecting using questionnaire with rating scale and data analysis with correlation and regression. The results of the research showed: Firtsly, there is a positive relationship between organizational climate with lecture job performance. Second, there is a positive relationship between work ethic with the lecture job perfrmance. Third, there is a positive relationship between organizational climate and work ethic simultaneously with the lecture job performance.
\end{abstract}

\section{Keywords: organizational climate, work ethic, and job performance}

\section{PENDAHULUAN}

Eksistensi sumber daya manusia yang berkualitas dibutuhkan oleh setiap organisasi agar sukses mewujudkan visi dan misinya. Sumber daya organisasi organisasi merupakan faktor terpenting untuk dapat melaksanakan fungsi organisasi secara optimal, baik pada level top management, middle maupun low management. Sumber daya manusia bersifat aktif dan dinamis, sedangkan faktor fasilitas dan dana merupakan faktor yang bersifat pasif, sehingga tanpa ada kemampuan yang memadai dari segenap SDM untuk mengelola fasilitas dan dana yang ada, maka keberadaan dana dan fasilitas tidak akan banyak memberikan manfaat. Oleh karena itulah, masalah kinerja karyawan senantiasa menjadi pusat perhatian, baik di kalangan akademisi kampus maupun praktisi, karena kinerja karyawan diyakini sebagai determinan terpenting bagi kinerja organisasi secara keseluruhan.

Persaingan yang ketat saat ini terjadi tidak hanya di lembaga-lembaga bisnis, tetapi juga sudah merambah pada sektor pendidikan. Tingkat persaingan dalam penyelenggaraan pendidikan khususnya untuk akademi perawatan saat ini juga berlangsung cukup ketat. Hal ini menuntut adanya antipasi yang sigap dari segenap institusi yang menyelenggarakan pendidikan Akademi Keperawatan agar dapat tetap eksis dan mampu bersaing.

Usaha untuk menghasilkan kinerja secara optimal perlu mengidentifikasi faktor-faktor yang mempengaruhinya. Salah satu faktor yang potensial berpengaruh terhadap kinerja adalah iklim organisasi. Iklim organisasi yang kondusif dalam sebuah organisasi akan mendorong karyawan untuk bekerja dalam situasi yang

*Dosen Akademi Keperawatan RS PGI Cikini. 
menyenangkan sehingga akarn akan dapat melakukan dengan sebaik-baiknya. Iklim organisasi yang kondusif, juga akan mendorong karyawan untuk melaksanakan tugas dan tanggung jawabnya dengan semaksimal mungkin.

Selain iklim organisasi, etos kerja juga merupakan faktor yang memiliki peranan penting dalam menentukan kinerja seorang pegawai. Etos kerja terkait dengan sikap seorang pekerja terhadap pekerjaannya sehari-hari, seperti tercemin dalam hal ketepatan waktu, kerja keras, melihat pekerjaan sebagai bentuk ibadah, dan cara menggunakan waktu luang. Ketepatan waktu misalnya merupakan hal penting dalam bekerja, karena menunjukkan suatu komitmen yang kuat dalam bekerja. Ketepatan waktu dapat dilihat dari ketepatan hadir dan pulang kerja atau dalam menyelesaikan pekerjaan. Kerja keras juga sangat dibutuhkan untuk dapat mendapatkan hasil kerja yang maksimal. Dengan adanya kerja keras, seorang pegawai akan giat dan tekun dalam bekerja serta berusaha secara maksimal untuk mendapatkan hasil kerja yang lebih baik.

Banyak organisasi yang telah menyadari pentingnya iklim organisasi dan etos kerja dalam meningkatkan kinerja. Namun dalam kenyataannya di banyak organisasi kondisinya masih belum sepenuhnya mendukung kinerja, seperti yang terjadi di lingkungan Akademi Keperawatan (Akper) di wilayah Jakarta Pusat. Sampai sejauh ini umumnya iklim organisasi di Akademi Keperawatan Jakarta Pusat masih belum mendukung peningkatan kinerja karyawan yang diindikasikan dengan kurangnya keluasaan karyawan dalam menjalankan tugasnya, kewenangan pengambilan keputusan terbatas, dan kurangnya umpan balik. Demikian pula dengan etos kerja, juga belum secara maksimal dimiliki dosen, seperti tercermin dengan kurangnya semangat kerja, kurangnya ketepatan waktu dan jiwa kerja keras yang belum dimiliki oleh banyak dosen.

Brumbrach dalam Armstrong (2006: 498) menjelaskan kinerja, "job performance means both behaviors and results. Behaviors emanate from the performer and transform performance from abstraction to action. Not just the instruments for results, behaviours are also outcomes in their own right - the product of mental and physical effort applied to tasks and can be judged apart from results." Kinerja mencakup perilaku dan hasil. Dari aspek perilaku, kinerja berasal dari pelaksana tugas dan mentransformsaikan kinerja dari yang abstrak menjadi tindakan. Perilaku juga bukan hanya instrumen untuk hasil, tetapi juga merupakan hasil dari dirinya sendiri (produk mental dan penerapan usaha fisik terhadap tugas) dan bisa juga dinilai bagian dari hasil. Viswesvaran dan Ones (2005: 354) mengungkapkan, "job performance refers to scalable actions, behaviors, and outcomes that employees engage in or bring about that are linked with and contribute to organizational goals". Kinerja adalah tindakan, perilaku dan hasil terukur yang dilakukan karyawan yang berhubungan dan berkontribusi terhadap tujuan organisasi.

Hanson dan Borman (2014: 143) juga menekankan konsep kinerja berhubungan perilaku yang relevan dengan pencapaian tujuan organisasi, sebagaimana dijelaskan, "job performance is defined as behavior that is relevant to the organization's goals and that can be measured in terms of the individual's contribution to 
organizational effectivenes". Sementara Campbell dalam Colquitt, LePine dan Wesson (2013: 33), mengungkapkan, "job performance is the value of the set of employee behaviors that contribute, either positively or negatively, to organizational goal accomplishment". Kinerja adalah nilai atas sekumpulan perilaku yang berkontribusi secara negatif atau positif terhadap pencapaian tujuan organisasi.

Hoy dan Miskel (2013: 116) menyatakan bahwa performance $=$ fungsi (ability $x$ motivation) atau dengan kata lain kinerja adalah fungsi dari kecakapan/kepandaian dan motivasi. Pengertian ini menunjukkan bahwa kinerja seseorang dipandang sebagai sesuatu yang ada sebagai pengaruh dari kemampuan dan motivasinya dalam bekerja.

Secara teoritis, kinerja ditentukan oleh banyak hal. Menurut Simamora yang dikutip Mangkunegara (2007 : 14), kinerja (performance) dipengaruhi oleh tiga faktor. Pertama adalah faktor individual yang terdiri dari: kemampuan dan keahlian, latar belakang dan demografi. Kedua yaitu faktor psikologis yang terdiri dari: persepsi, attitude, personality, pembelajaran, dan motivasi. Ketiga adalah faktor organisasi yang terdiri dari: sumber daya, kepemimpinan, penghargaan, struktur, dan job design. Sementara menurut Timpe yang dikutip Mangkunegara (2007: 14), faktorfaktor kinerja terdiri dari faktor internal dan faktor eksternal. Faktor internal (disposional) yaitu faktor yang dihubungkan dengan sifat-sifat seseorang. Faktor eksternal yaitu faktor-faktor yang mempengaruhi kinerja seseorang yang berasal dari lingkungan, seperti prilaku, sikap dan tindakan-tindakan rekan kerja, bawahan atau pimpinan, fasilitas kerja, dan iklim organisasi.

Dalam usaha melihat kinerja seseorang, perlu ditetapkan indikator yang terukur. Berkenaan dengan kinerja ini, terdapat pendapat yang mengemukakan bahwa kinerja memiliki beberapa indikator, yaitu: 1) pengembangan diri, 2) kerja tim, 3) komunikasi, 4) jumlah produk yang dihasilkan dan 5) keputusan yang dibuat (Alan dan Barker, 1996: 13).

Bagi Mondy, Sharplin dan Flippo (1995: 509), kinerja dapat dilihat melalui sejumlah standar. Pertama, adalah standar waktu, menyatakan lamanya waktu yang seharusnya diselesaikan untuk membuat produk atau melakukan jasa tertentu. Kedua, standar produktivitas, yaitu standar yang didasarkan pada jumlah produk atau jasa yang harus dihasilkan dalam jangka waktu tertentu. Ketiga, standar biaya, merupakan standar yang didasarkan pada biaya dihubungkan dengan barang atau jasa yang diproduksi. Keempat, standar kualitas, yakni standar yang didasarkan pada tingkat kesempurnaan sebagaimana yang dikehendaki. Kelima, standar perilaku, yaitu standar yang didasarkan pada bentuk perilaku yang diinginkan dari pekerja dalam suatu organisasi.

Sementara itu, dalam melihat kinerja seseorang, Furtwengler (2002: 86) menyebutkan aspek-aspek yang dapat dijadikan ukuran untuk menilai kinerja, yaitu kecepatan, kualitas, layanan, nilai, keterampilan interpersonal, mental untuk sukses, terbuka untuk berubah, kreativitas, keterampilan berkomunikasi, inisiatif, dan perencanaan organisasi. 
Banyak ahli yang menjelaskan tentang pengertian iklim organisasi. Davis dan Newstrom (1993: 21) menyatakan bahwa iklim organisasi adalah lingkungan manusia di mana di dalamnya anggota organisasi melakukan pekerjaan mereka. Stoner (1987: 331) menyatakan "organization climate in the set of characteristik that describe an organization and that: 1) distinguishes the organization from other organization, 2) are relatively enduring over time, and 3) influence the be havior of people in the organization." Iklim organisasi merupakan salah satu dari yang membedakan organisasi yang satu dan yang lainnya yang dapat dirasakan jika seseorang masuk ke dalamnya.

Taguiri sebagaimana dikutip Furnham (1977: 580) menjelaskan tentang iklim organisasi, "organizational climate is a relatively enduring quality of the internal environment of an organization that: (a) is experienced by its members, (b) influences their behavior, and (c) can be described in terms of the values of a particular set of characteristics (or attributes) of the organizations." Iklim organisasi adalah kualitas lingkungan internal organisasi yang bertahan relatif lama meliputi: (a) pengalaman anggota organisasi, (b) mempengaruhi perilaku, dan (c) dapat dijelaskan dalam istilah nilai atas seperangkat karakteristik atau atribut khusus organisasi.

Harrison dan Shirom dalam Armstrong (2012: 127) menjelaskan iklim organisasi, "organizational climate refers to 'members' perceptions of organizational features such as decision making, leadership and norms about work". Iklim organisasi berarti persepsi anggota organisasi atas fitur-fitur organisasi seperti pengambilan keputusan, kepemimpinan dan normat tentang kerja. Selanjutnya Moran dan Volkwein yang dikutip Kusluvan (2003: 458) menjelaskan iklim organisasi adalah karakteristik organisasi yang bertahan relatif lama yang membedakannya dengan organisasi lain dengan karakteristik: (a) berbentuk persepsi kolektif anggota organisasi yang meliputi dimensi otonomi, kepercayaan, kohesivitas, dukungan, pengakuan, inovasi, dan keadilan; (b) dihasilkan oleh interaksi anggota organisasi; (c) memberikan landasan untuk menginterpretasikan situasi, (d) mencerminkan norma, nilai dan sikap umum atas budaya organisasi, dan (e) tindakan sebagai sumber pengaruh untuk membentuk perilaku.

Pendapat lain dari Ivancevich, Konopaske dan Matteson (2008: 528) mengenai iklim organisasi yaitu, "organizational climate is a set of properties of the work environment, perceived, directly or indirectly by the employees, that assumsed to be a major force in influencing employee behavior. Iklim organisasi adalah seperangkat sifat-sifat dari lingkungan kerja yang dipersepsikan oleh pekerja baik secara langsung maupun tidak langsung dan hal itulah yang diasumsikan menjadi kekuatan utama yang mempengaruhi perilaku para pekerja.

Koys \& DeCotiis yang dikutip Wirawan (2007: 132) mengembangkan delapan dimensi iklim organisasi berdasarkan pendekatan psikologis, yaitu: Otonomi (autonomy), Kebersamaan (cohesion), Kepercayaan (trust), Tekanan (pressure), Dukungan (support), Pengakuan (recognition), Kewajaran (fairness), dan Inovasi (innovation). Sementara Stringer yang dikutip Wirawan (2007: 131), menyebutkan bahwa iklim organisasi memiliki enam dimensi: Struktur (structure), Standar-standar 
(standards), Tanggung jawab (responsibility), Penghargaan (recognition), Dukungan (support), dan Komitmen (commitment).

Menurut Hoy dan Miskel (2013: 140) iklim organisasi terdapat dua tipe, yaitu iklim terbuka dan iklim tertutup. Ciri khusus iklim organisasi yang terbuka antara lain: perilaku pimpinan yang dinamis, yang menggerakkan organisasi melalui contoh perilaku yang nyata (thrust); semangat kerja yang tumbuh karena pemenuhan tugas maupun pemenuhan kebutuhan sosial (esprit) serta rendahnya kecenderungan karyawan untuk berganti-ganti tugas, tanpa menekuni pekerjaan yang ditugaskan kepadanya (disengagement). Iklim organisasi yang tertutup sebenarnya merupakan antisitetis dari iklim yang terbuka dengan ciri thrust dan esprit yang rendah serta disengagement yang tinggi. Perbedaaan iklim yang terbuka dan iklim yang tertutup terutama tam pak pada esprit, trust dan perilaku pimpinan yang akrab dan bersahabat (Consideration).

McShane dan Von Glinow (2008: 48) menjelaskan etika "the study of moral principles or values that determine whether actions are right or wrong and outcomes are good or bad. People rely on their ethical values to determine "the right thing to do." Etika merujuk pada prinsip-prinsip atau nilai-nilai moral yang menentukan apakah suatu tindakan adalah benar atau salah dan hasilnya baik atau buruk. Orang yang percaya atas nilai-nilai etika menentukan kebenaran sesuatu untuk dilakukan. Menurut Bateman dan Snell (2007: 151), etika diartikan sebagai system of rules that governs the ordering of values. Definisi ini menjelaskan bahwa etika adalah sistem aturan-aturan yang mengatur urutan nilai.

Etos kerja pertama kali muncul diyakini berasal dari Amerika yang merupakan hasil dari reformasi Protestan yang membentuk nilai-nilai dan perilaku baru guna mendukung perkembangan ekonomi dan mempercepat ekonomi kapitalis. Merujuk pada tulisan-tulisan Marthin Luther, John Calvin dan Benjamin Franklin, Weber mengidentifikasikannya dengan istilah etika Protestan atau dikenal pula dengan istilah etos kerja protestan (Protestant Work Ethics). Franklin misalnya, mengajukan filosofi hidup seperti pengendalian diri (temperance), keheningan (silence), keteraturan (order), resolusi (resolution), hemat (frugality), ketulusan (sincerity), keadilan (justice), moderasi (moderation), kebersihan (cleanliness), kedamaian (tranquillity), kesucian (chastity), dan kerendahan hati (humility) (Modrack, 2008: 1).

Menurut Barnhart (dalam Grobler dan Mestry, 2006: 5), etos kerja diturunkan dari sosiologi yang diartikan sebagai sikap kelompok atau masyarakat terhadap pekerjaan, khususnya sikap atau keyakinan bahwa bekerja adalah baik untuk manusia dan lebih tinggi pada skala nilai di masyarakat dibandingkan dengan bermain atau membuang-buang waktu. Oleh karena itu, etos kerja mencerminkan nilai-nilai budaya masyarakat. Miller, Woehr dan Hudspeth (2002: 455) secara sederhana mendefinisikan etos kerja sebagai konstelasi antara sikap dengan keyakinan-keyakinan yang berhubungan dengan perilaku kerja. Etos kerja memiliki karakteristik yang multidimensional, berhubungan dengan aktivitas pekerjaan 
secara umum, dapat dipelajari, menunjukkan sikap dan keyakinan, dan terpisah dengan keyakinan agama tertentu.

Hasil penelitian yang dilakukan oleh Porter (2004: 339) menunjukkan beberapa ciri orang yang memiliki etos kerja tinggi, yaitu: (1) tepat waktu, (2) bangga dengan apa yang dilakukan, (3) mandiri, (4) bertanggungjawab, (5) mengambil inisiatif, dan (6) menyelesaikan tugas sampai tuntas. Untuk mengukur etos kerja digunakan indikator yang berbeda-beda. Miller, Woehr dan Hudspeth yang dikutip oleh Meriac, Poling, dan Woehr (2009: 210) menggunakan tujuh dimensi untuk mengukur etos kerja, yaitu: (1) pemusatan kerja (centrality of work), yaitu keyakinan terhadap pentinyanya pekerjaan, (2) kepercayaan diri (self reliance), yaitu berjuang secara mandiri dalam menjalankan tugas sehari-hari, (3) kerja keras (hard work), adalah keyakinan terhadap kabajikan kerja keras, (4) tidak menyia-nyiakan waktu luang (lesiure), yaitu pentingnya mengisi pekerjaan pada waktu-waktu luang, (5) moralitas (morality), keyakinan terhadap keberadaan moral, (6) menunda gratifikasi (delay of gratification), berorientasi masa depan dan menunda hadiah, dan (7) tidak membuang waktu (wasted time), yaitu sikap dan kepercayaan yang aktif dan produktif menggunakan waktu.

Sementara Juzanek (1978: 669) dengan merangkum hasil penelitian terdahulu menyebutkan dimensi etos kerja, yaitu: (1) kehendak untuk bekerja, (2) pemusatan kerja dalam kehidupan karir seseorang, (3) tanggungjawab, disiplin kerja dan kualitas personal lain, dan (4) persepsi kerja sebagai kewajiban sosial terhadap masyarakat.

\section{METODE}

Penelitian ini menggunakan pendekatan kuantitatif dengan metode survei. Responden penelitian adalah dosen Akademi Keperawatan di Jakarta Pusat yang berjumlah 54 orang yang diambil dengan tekinik acak sederhana. Pengumpulan data menggunakan kuesioner skala rating 1-5. Hasil perhitungan validitas variabel kinerja diketahui dari 35 item pernyataan ada tiga yang tidak valid diperoleh koefisien Alpha 0,960; variabel iklim organisasi diketahui dari 40 item pernyataan terdapat 4 item pernyataan yang tidak valid dengan koefisien Alpha 0,971; dan variabel etos kerja diketahui dari 35 item pernyataan terdapat tiga item yang tidak valid dengan koefisien Alpha 0,958.

\section{HASIL DAN PEMBAHASAN}

\section{Hubungan antara iklim organisasi dengan kinerja}

Hasil pengujian hipotesis pertama menunjukkan bahwa iklim organisasi memiliki hubungan positif dengan kinerja dosen. Koefisien korelasi yang diperoleh $\left(\mathrm{r}_{\mathrm{y} 1}\right)=0,578$ dengan $\mathrm{t}$-hitung $=5,114>\mathrm{t}$-tabel $=2,407$, dan koefisien determinasi $=33,5 \%$ yang dijelaskan melalui persamaan regresi $\hat{Y}=70,669+0,394 X_{1}$. Hubungan positif 
memiliki makna bahwa semakin kondusif iklim organisasi, maka semakin tinggi kinerja dosen.

Dalam bekerja iklim organisasi yang kondusif sangat diperlukan untuk mendapatkan hasil kerja yang optimal. Iklim organisasi merupakan situasi eksternal, yang merupakan akumulasi dari berbagai faktor di sekitar lingkungan kerja. Dalam hal ini, kondisi iklim organisasi dapat dilihat dari otonomi, kebersamaan, kepercayaan, tekanan, dukungan, pengakuan, dan kewajaran. Sebagai contoh untuk aspek otonomi, sangat dibutuhkan dalam bekerja karena dengan adanya otonomi yang cukup akan mendorong kreativitas para pegawai, sehingga hasil kerja yang diperoleh juga akan lebih baik. Kebersamaan juga penting, karena kebersamaan akan mendorong timbulnya suasana nyaman dalam organisasi dan kerjasama juga akan terjalin dengan baik. Demikian pula dengan faktor-faktor lain seperti kepercanaan, dukungan, pengakuan dan kewajaran juga diperlukan untuk memaksimalkan hasil kerja.

Secara teoretik hubungan antara iklim organisasi dengan kinerja dikemukakan Dreyfus (1994: 188), "perceptions of a positive organizational climate were significantly related to job satisfaction in work organizations, unit effectiveness in a military setting and employee performance." Persepsi tentang iklim organisasi yang positif salah satunya berhubungan dengan kinerja. Penelitian terdahulu yang dilakukan Hanifah dan Kurniady (2013: 1) juga menunjukkan bahwa iklim organisasi memiliki hubungan yang sanga kuat dengan kinerja. Penelitian lain yang dilakukan Setiawan (2015: 23) juga menunjukkan adanya hubungan yang signifikan antara iklim organisasi dengan kinerja. Dengan demikian hasil penelitian ini memberikan dukungan atau memperkuat kajian teoritik dan hasil penelitian terdahulu tentang adanya hubungan antara iklim organisasi dengan kinerja.

\section{Hubungan antara etos dengan kinerja}

Hasil pengujian hipotesis kedua membuktikan bahwa etos kerja memiliki hubungan positif dengan kinerja dosen. Koefisien korelasi yang diperoleh $\left(\mathrm{r}_{\mathrm{y} 2}\right)=$ 0,623 dengan $t_{\text {-hitung }}=5,738>\mathrm{t}_{\text {-tabel }}=2,407$, koefisien determinasi $=38,8 \%$ yang dijelaskan dengan persamaan regresi $\hat{Y}=61,297+0,471 X_{2}$. Hubungan positif menunjukkan bahwa semakin baik etos kerja, maka semakin tinggi kinerja dosen.

Etos kerja yang positif dibutuhkan agar seseorang memiliki kinerja yang baik. Etos kerja adalah adalah sikap seorang pekerja terhadap pekerjaannya yang ditunjukkan dalam bentuk kerja keras, kemandirian, ketepatan waktu, bertanggungjawab, bangga terhadap pekerjaan, dan tidak menyia-nyiakan waktu luang. Dengan demikian etos kerja merefleksikan bagaimana seorang pegawai menyikapi dan melaksanakan pekerjaannya. Oleh karena itu, etos kerja akan berkaitan erat dengan hasil yang diperoleh dalam bekerja. Ketepatan waktu misalnya merupakan hal penting dalam bekerja, karena menunjukkan suatu komitmen yang kuat dalam bekerja. Ketepatan waktu dapat dilihat dari ketepatan hadir dan pulang kerja atau dalam menyelesaikan pekerjaan. Kerja keras juga sangat 
dibutuhkan untuk dapat mendapatkan hasil kerja yang maksimal. Dengan adanya kerja keras, seorang pegawai akan giat dan tekun dalam bekerja serta berusaha secara maksimal untuk mendapatkan hasil kerja yang lebih baik.

Secara teoretik hubungan antara etos kerja dengan kinerja diungkapkan oleh Jeston dan Nelis (2008: 161), "while most social scientists believe that both internal and external factors contribute to job performance, 35\% of managers believed that the individual's work ethic has the greatest impact on job performance". Penjelasan ini menunjukkan bahwa etos kerja memberikan kontribusi terhadap kinerja individu sebesar 35\%. Promislo, Giacalone, dan Jurkiewicz (2013: 3) juga menjelaskan " $a$ company's ability to foster an ethical corporate culture is linked to an increased ability to attract employees and enhance job performance." Ini berarti bahwa kemampuan untuk memperkuat budaya etik berhubungan dengan kemampuan untuk meningkatkan kinerja. Penelitian terdahulu yang dilakukan Husni (2014: 341) juga memberikan bukti bahwa etos kerja memiliki hubungan positif dengan kinerja. Penelitian lainnya dilakukan Nasrun (2011: vii) yang juga menunjukkan adanya hubungan antara etos kerja dengan kinerja. Dengan demikian hasil yang diperoleh dari penelitian ini semakin memperkuat dan mendukung penelitian terdahulu mengenai adanya hubungan antara etos kerja dengan kinerja.

\section{Hubungan antara iklim organisasi dan etos kerja secara bersama-sama dengan kinerja}

Hasil penelitian ini juga membuktikan bahwa iklim organisasi dan etos kerja secara bersama-sama memiliki hubungan dengan kinerja. Koefisien korelasi yang diperoleh $\left(\mathrm{R}_{\mathrm{y} 12}\right)=0,681$ dengan $\mathrm{F}_{\text {-hitung }}=22,068>\mathrm{F}_{\text {-tabel }}=5,08$ koefisien determinasi= $46,4 \%$ yang dijelaskan melalui persamaan regresi $\hat{Y}=50,606+0,228 X_{1}+0,329 X_{2}$. Dari hasil perhitungan koefisien korelasi parsial hubungan iklim organisasi dengan kinerja yang dikontrol etos kerja diiperoleh koefisien korelasi parsial $r_{\mathrm{y} 1.2}=0,353$ dengan $t$-hitung $(2,694)>t$-tabel $(2,407)$, yang berarti iklim organisasi tetap memiliki hubungan signifikan dengan kinerja dosen jika dikontrol oleh etos kerja.

Hasil penelitian yang menunjukkan hubungan signifikan iklim organisasi dan etos kerja secara bersama-sama dengan kinerja karena secara parsial iklim organisasi dan etos kerja diketahui memiliki hubungan dengan kinerja. Dengan demikian secara bersama-sama iklim organisasi dan etos kerja juga memiliki hubungan dengan kinerja. Oleh karena itu, apabila kedua faktor tersebut saling mendukung, maka akan dapat meningkatkan kinerja. Namun sebaliknya, jika kondisi di dalam organisasi tidak kondusif dan tidak didukung dengan etos kerja yang baik, maka dapat menyebabkan kinerja menurun. Kinerja merupakan variabel yang identik dengan produktivitas.

Secara teoretik Nasution, Mahargiono dan Soesatyo (2016: 262) menjelaskan keterkaitan antara faktor iklim organisasi dan etos kerja dengan kinerja yang ditunjukkan dengan tingkat produktivitasnya, "these result s indicate that leadership style variable, organizational climate, and work ethic which is already in the test, an effect simultaneously to variable working productivity". Penjelasan tersebut menunjukkan 
bahwa iklim organisasi dan etos kerja berhubungan dengan kinerja. Penelitian terdahulu yang dilakukan Dodi, Yunus, dan Amri (2013: 98) juga menunjukkan bahwa iklim organisasi dan etos kerja secara bersama-sama berpengaruh terhadap kinerja. Demikian pula dengan penelitian Marjaya, Susila, dan Yudiaatmaja (2016: 1), juga menunjukkan bahwa iklim organisasi dan etos kerja berhubungan dengan kinerja. Dengan hasil demikian, maka penelitian semakin mendukung dan memperkuat model teoritis dan empiris mengenai adanya hubungan antara iklim organisasi dan etos kerja dengan kinerja.

\section{PENUTUP}

Kesimpulan: 1) terdapat hubungan positif iklim organisasi dengan kinerja. Artinya, semakin baik atau kondusif iklim organisasi, maka semakin tinggi kinerja dosen, 2) terdapat hubungan positif antara etos kerja dengan kinerja. Artinya, semakin baik etos kerja, maka semakin tinggi kinerja dosen, dan 3) terdapat hubungan positif antara iklim organisasi dan etos kerja secara bersama-sama dengan kinerja. Artinya, semakin kondusif iklim organisasi dan semakin baik etos kerja, maka semakin tinggi kinerja dosen.

Saran: Iklim organisasi perlu diperbaiki dengan memperbaiki kualitas hubungan dan komunikasi antar warga kampus, sehingga pimpinan harus menciptakan suasana kekerabatan dan komunikasi yang harmonis, mengembangkan suasana toleransi, saling menghargai, dan saling menghormati, serta menyediakan fasilitas kerja yang memadai bagi dosen. Sementara untuk meningkatka etos kerja, dosen harus terlebih dahulu diberikan pemahaman dan pengetahuan yang memadai tentang pentingnya etos kerja dan perlunya keteladanan dari pimpinan mempraktekkan etos kerja di kampus.

\section{DAFTAR RUJUKAN}

Armstrong, Michael, A Handbook of Human Resource Management Practice, London: Kogan Page, 2006.

Armstrong, Michael, A Handbook of Human Resource Management Practice, London: Kogan Page, 2012.

Bateman, Thomas S. and Scott A. Snell, Management: Leading $\mathcal{E}$ Collaborating in a Competitive World, New York: McGraw-Hill, 2007.

Colquitt, Jason A., Jeffery A. LePine dan Michael J. Wesson, Organizational Behavior: Improving Performance and Commitment in the Workplace, New York: McGrawHill Companies, Inc., 2013. 
Davis, Keith, dan John W. Newstrom, Organizational Behavior: Human Behavior at Work. New York: McGraw-Hill, 1993.

Dreyfus, C.R., Measuring the People Side of Quality, ed. J.D. Symonds, Dordrecht: Springer Science, 1994.

Furnham, Adrian, The Psychology of Behaviour at Work: The Individual in the Organization, Hove Eas Sussex: Psychology Press, 1977.

Furtwengler, Dale, Penilaian Kinerja, Yogyakarta: Andi, 2002

Grobler, Bennie and Raj Mestry, The work ethic of principals in the management of change: A South African perspective, paper, http:// www.acel.org.au/conf07/ papers.php, 2006.

Hanifah, Rina dan Dedy Achmad Kurniady, "Hubungan Iklim Organisasi dengan Kinerja Pegawai pada Sentra Pendidikan Bank Rakyat Indonesia Bandung", Jurnal Adminisistrasi dan Manajemen Pendidikan, Vol. I, 2013.

Hanson, Mary Ann dan Walter C. Borman, Citizenship Performance: An Integrative Review and Motivational Analysis, eds. Winston Bennett, Charles E. Lance, dan David J. Woehr, New York: Psychology Press, 2014.

Hoy, Wayne K. dan Cecil G. Miskel, Educational Administration: Theory, Research and Prantice, New York: Random House, Inc, 2013.

Husni, Irda, "Hubungan Etos Kerja dengan Kinerja Guru di Smk Negeri 1 Lubuk Sikaping", Jurnal Administrasi Pendidikan, Vol. 2 No. 1, 2014.

Ivancevich, J. M., R. Konopaske dan M.T. Matteson, Organizational Behaviour and Management, New York: McGraw-Hill/Irwin, 2008

Jeston, By John dan Johan Nelis, Management by Process: A Roadmap to Sustainable Business Process Management, Burlington: Butterworth-Heinemann, 2008.

Kusluvan, Salih, Managing Employee Attitudes and Behaviors in the Tourism and Hospitaility Industry, New York: Nova Science Publishers, Inc., 2003.

Mangkunegara, A.A. Prabu, Manajemen Sumber Daya Manusia Perusahaan, Bandung: Remaja Rosdakarya, 2007.

Marjaya, Putu Hery Tindra, Gede Putu Agus Jana Susila, dan Fridayana Yudiaatmaja, "Pengaruh Iklim Organisasi dan Etos Kerja terhadap Kinerja Karyawan Bagian Produksi", Jurnal Jurusan Manajemen, Vol 6, No 3, 2016, 
McShane and Von Glinow, Organizational Behavior, New York: McGraw-Hill, 2008.

Meriac, John P., Taylor L. Poling, and David J. Woehr, Are there gender differences in work ethic? An examination of the measurement equivalence of the multidimensional work ethic profile, Journal of Personality and Individual Differences, Vo. 47, 2009.

Miller, Michael J., David J. Woehr and Natasha Hudspeth, The meaning and measurement of work ethic: Construction and initial validation of a multidimensional inventory, Journal of Vocational Behavior, 2002, Vol. 60.

Modrack, Simone, The Protestant Work Ethic revisited: a promising concept or an outdated idea? January 2008. ISSN Nr. 1011-9523. Wissenschaftszentrum Berlin für Sozialforschung (WZB), Social Science Research Center Berlin.

Mondy, R. Wayne, Arthur Sharplin, \& Edwin B. Flipo, Management: Concepts and Practices, Fourth Edition, Boston: Allyn and Bacon, 1995.

Nasrun, Ade, "Hubungan antara Etos Kerja dan Sikap Amanah dengan Kinerja Guru pada SMA-SMA Islam Yayasan Pesantren Islam Al-Azhar", Tesis, Unversitas Indonesia, 2011.

Nasution, Ade Parluangan, Ponco Bambang Mahargiono dan Yoyok Soesatyo, "Effect of Leadership Styles, Organizational Climate and Ethos of Work on Employee Pro ductivity of PT. HP Metals Indonesia the Powder Coating", International Journal of Business and Management; Vol. 11, No. 2; 2016.

Porter, Gayle, A "career" work ethic versus just a job, Journal of European Industrial Training, 29(4), 2004.

Promislo, Mark D., Robert A. Giacalone, dan Carole L. Jurkiewicz, Ethical Impact Theory: Unethical Work Behavior and Well-Being, eds. Robert A. Giacalone dan Mark D. Promislo, New York: Routledge, 2013.

Setiawan, Kiki Cahaya, "Pengaruh Iklim Organisasi terhadap Kinerja Karyawan Level Pelaksana di Divisi Operasi PT. Pusri Palembang", Jurnal Psikologi Islami, Vol. 1, No. 1, 2015.

Viswesvaran, Chockalingam dan Deniz S. Ones, Job Performance: Assessment Issues in Personnel Selection, eds. Arne Evers, Neil Anderson, dan Olga Smit-Voskuijl, Malden: Blackwell Publishing Ltd., 2005.

Wirawan, Budaya dan Iklim Organisasi, Jakarta: Salemba Empat, 2007. 